\title{
Trace Elements Adsorption by Natural and Chemically Modified Humic Acids
}

Leonid Perelomov ${ }^{1 *}$, Binoy Sarkar ${ }^{2}$, David Pinsky $^{3}$, Yury Atroshchenko ${ }^{1}$, Irina Perelomova $^{4}$, Loik Mukhtorov $^{1}$, Anton Mazur ${ }^{5}$

${ }^{1}$ Tula State Lev Tolstoy Pedagogical University, Lenin Avenue, 125, Tula, 300026, Russia

E-mail:perlomov@rambler.ru

${ }^{2}$ Lancaster Environment Centre, Lancaster University, Lancaster, LAl 4YQ,

United Kingdom

E-mail: b.sarkar@lancaster.ac.uk

${ }^{3}$ FIBCI Institute of Physico-Chemical and Biological Problems of Soil Science, Russian Academy of Sciences, ul. Institutskaya, 2, Moscow Region, Pushchino, 142290, Russia

E-mail: pinsky43@mail.ru

${ }^{4}$ Tula State University, Lenin Avenue, 92, Tula, 300026, Russia

E-mail:ketava@rambler.ru

${ }^{5}$ St. Petersburg State University, Universitetskaya nab., 7/9, St. Petersburg, 199034, Russia

E-mail: a.mazur@spbu.ru

*corresponding author

\section{Abstract}

Humic substances (HS) with or without chemical modification can serve as environmentally benign and inexpensive adsorbents of potentially toxic trace elements (PTTEs) in the environment. The present study investigated the absorption of $\mathrm{Pb}, \mathrm{Zn}, \mathrm{Cu}$, and $\mathrm{Ni}$ by natural and potassium persulfate $\left(\mathrm{K}_{2} \mathrm{~S}_{2} \mathrm{O}_{8}\right)$ modified humic acids (HA) isolated from a lowland peat through batch experiments. The adsorption of the studied PTTEs on the natural HA was satisfactorily described by the Langmuir isotherm model with maximum monolayer adsorption capacities of 318.2, 286.5, 225.0 and $136.8 \mathrm{mmol} / \mathrm{kg}$ for $\mathrm{Pb}, \mathrm{Cu}, \mathrm{Zn}$ and $\mathrm{Ni}$, respectively. A thorough characterization of the natural and modified HA using ${ }^{13} \mathrm{C}$ nuclear magnetic resonance (NMR) spectroscopy demonstrated that the chemical modification of 
natural HA with $\mathrm{K}_{2} \mathrm{~S}_{2} \mathrm{O}_{8}$ led to an increase in the content of carboxyl groups, and ketone and quinoid fragments in the HA structure. Consequently, the modified HA absorbed 16.3, 14.2, 10.6 and $6.9 \%$ more $\mathrm{Pb}, \mathrm{Ni}, \mathrm{Zn}$ and $\mathrm{Cu}$, respectively, than the original natural HA. The isotherm data modelling together with adsorbent characterization suggested that the adsorption of PTTEs was controlled mainly by chemisorption mechanisms where inner-sphere complexations of metal ions with HA functional groups took place.

Keywords: Humic substances; Potentially toxic trace elements; Persulfate oxidation; Sorption

\section{Introduction}

Modern technologies for cleaning the environment from chemical pollution require the development and application of qualitatively new and effective materials characterized by increased absorption capacity, selectivity and environmental friendliness. In addition, concerns about the easy availability of the remediation materials and their low cost are extremely important. Humic substances (HS) that are the most widespread natural non-living organic materials in soils, as well as in all terrestrial and aquatic environments, fully meet the above requirements of being environmentally benign, abundantly available and inexpensive (Loffredo and Senesi, 2006). The HS are formed in the aquatic and terrestrial environments by the decomposition of plants, animals and microorganisms. On an industrial scale, HS are obtained from peat, sapropel and coal, where their global reserves reach gigatons (Perminova and Hatfield, 2005).

It is well known that humic acids (HA) and fulvic acids (FA) which are the main parts of HS, and cannot be regarded as single molecules described by their chemical formulas (Stevenson, 1994). Despite the diversity of opinions regarding the chemical and physicochemical structure of humic substances, all authors univocally acknowledge a significant fact that various functional groups of humic 
substances dissociate differently according to the acidity or alkalinity of the medium (Stevenson, 1994; Ghabbour and Davies, G., 2007).

The reactivity of HA depends on the content of aromatic conjugates and degree of condensation, as well as to a significant degree on the number of different functional groups (Orlov, 1995; Boguta and Sokołowska, 2016). HAs contain chemically reactive functional groups of various nature (mainly carboxylic and phenolic groups, but also alcoholic hydroxyls, carbonyls, etc.), which renders the HA polymer with an acidic reaction. Humic carboxylic $(-\mathrm{COOH})$ and phenolic ($\mathrm{OH})$ groups are mainly involved in the formation of metal-humic acid complexes (Datta et al., 2001). Potentially toxic trace elements (PTTE) (e.g., heavy metals) may have toxic effects to living organisms including human at high concentrations in the environment (Perelomov et al, 2016; Vardhan et al., 2019). PTTE bound by insoluble HS are relatively immobile in nature and not bioavailable. On the other hand, binding by smaller organic molecules such as low molecular-weight organic acids may increase the trace elements' mobility in the environment (Kabata-Pendias and Pendias, 1992; Perelomov et al., 2018).

Purposeful chemical modification of HA can change their composition and increase the content of the necessary functional groups and thereby improve their PTTE sorption properties. Among various possible ways, HA can be modified by carrying out an oxidation (destroying or mild) (Schnitzer and Ortiz de Serra, 1973; Meneghel et al., 1972; Hayes and Swift, 1978; Martin et al., 1982), reduction (Lebedeva et al., 2005), or introduction of organic molecule fragments into the structure of HA (Perminova et al., 2005).

For example, the possibility of chemical modification of peat HA by reduction with $\mathrm{SnCl}_{2}$ and $\mathrm{NaBH}_{4}$, and also by carboxylation using the Kolbe method was studied by Lebedeva et al. (2005). The experimental results showed that during the treatment of $\mathrm{HA}$ by $\mathrm{SnCl}_{2}$ in an alkaline conditions, significant structural changes occurred: quinoid groups were reduced to phenolic, the number of carboxyl groups in air did not change, and in the atmosphere of $\mathrm{CO}_{2}$ increased. $\mathrm{NaBH}_{4}$ reduced 
quinoid groups to phenolic, ketone groups to alcohol hydroxyls, while the number of carboxyl groups remained practically unchanged.

Oxidative methods have also been frequently and successfully used for the degradation and modification of HS (Hayes and Swift, 1978). The most widely used methods for the oxidation of HS include reactions with permanganate, hypochlorite, nitrobenzene, hydrogen peroxide, peracetic acid and nitric acid (Griffith and Schnitzer, 1989; Yuthawong et al., 2019; Zhou et al., 2019). Alkaline solutions of cupric-, mercuric- and silver- oxides have also been used to degrade HS (Martin and Gonzalez-Vila, 1984; Hatten and Goñi, 2016). A partial degradation with solutions of potassium permanganate $\left(\mathrm{KMnO}_{4}\right)$ of a large number of $\mathrm{HA}$ from soils, waters and sediments yielded aliphatic, phenolic and benzenecarboxylic acids as the major fragments (Gjessing, 1976). An oxidation by oxides also yielded aliphatic, phenolic and benzenecarboxylic acids but the relative amounts were not the same as for potassium permanganate oxidation (Schnitzer and Ortiz de Serra, 1973). The oxidation of HS is also possible under acidic conditions. Meneghel et al. (1972) used peracetic acid as an oxidizing agent, but the percentage of degradation of the initial HS, the total yield of fragments and the identified types of structures turned out to be similar to those obtained by the methods of permanganate oxidation and oxidation by copper oxide. Lately technology of photocatalytic oxidation with $\mathrm{TiO}_{2}$ powders as catalyst was investigated in the degradation and decolorization of HS in natural and wastewaters (Tung et al., 2019; Valencia et al., 2018).

However, drastic conditions of reaction and relatively high temperature could lead to serious alterations in the chemical structures of the initial HS with the possibility of secondary reactions in the presence of oxygen. For a non-destructive oxidation, Martin and co-authors (1982) proposed a method that is carried out in acidic conditions using a potassium persulfate $\left(\mathrm{K}_{2} \mathrm{~S}_{2} \mathrm{O}_{8}\right)$ reagent, which was traditionally used by oceanographers to determine the $\mathrm{C}$ content in sea water (Sharp, 1973). Subsequently, a number of other methods were proposed for non-destructive oxidation of HA, most of which affected the phenolic groups in the HA composition (Martin and Gonzalez-Vila, 1984). 
In recent years classical methods for the oxidation of phenols taken from organic chemistry have been used for the mild oxidation of HA (Perminova et al., 2005). Oxidizing agents capable of easily releasing oxygen such as hydrogen peroxide or $\bullet \mathrm{OH}$ radical (Fenton's reagent), organic peroxides, iodic acid $\left(\mathrm{HIO}_{4}\right)$, persulfates, lead tetraacetate $\left(\mathrm{Pb}\left(\mathrm{C}_{2} \mathrm{H}_{3} \mathrm{O}_{2}\right)_{4}\right)$ and potassium nitrosodisulfonate (Fremy's salt) can oxidize phenols causing their hydroxylation, quinone formation and polymerization (Nguyen et al., 2003). Initially, a free phenoxyl radical $\left(\mathrm{C}_{6} \mathrm{H}_{5} \mathrm{O} \bullet\right.$ ) is formed, which then quickly turns into various complex oxidation products. During the oxidation of phenol by strong oxidizing agents, not only $\mathrm{C}$ bound to hydroxyl is oxidized, but also an atom existing in the para position relative to hydroxyl, results in the formation of benzoquinone (Uliana et al., 2008).

One of the reagents used for the oxidation of aromatic phenols and amines, as already mentioned, is $\mathrm{K}_{2} \mathrm{~S}_{2} \mathrm{O}_{8}$. The use of $\mathrm{K}_{2} \mathrm{~S}_{2} \mathrm{O}_{8}$ for the oxidation of aromatic phenols is called the Elbs reaction, and the oxidation of aromatic amines is called the Boyland-Sims reaction (Behrman, 2006). Both the Elbs and Boyland-Sims reactions are characterized by nucleophilic displacements on a peroxide oxygen of the peroxydisulfate ion. In the Elbs oxidation, the nucleophile is a phenolate anion (or, a tautomer), and in the Boyland-Sims oxidation, it is a neutral aromatic amine. The products are aromatic sulfates whose orientation relative to the phenolic group is preferentially para in the Elbs oxidation and ortho in the Boyland-Sims case (Behrman, 2006) (Fig. 1). The sulfate products are useful in the synthesis themselves or may be hydrolyzed in acid to form dihydric phenols (or aminophenols) (Behrman, 2006).

Perminova et al. (2005) using a classical titrimetric method (barium hydroxide to determine total acidity and calcium acetate to determine carboxyl groups) studied the changes in the contents of various functional groups in HA from leonardite, hydroxylated by Elbs reaction, and then reduced by sodium sulfite. In those investigations, an increase in the total acidity and content of carboxyl groups in the modified HA in comparison with the initial ones was established. A decrease in the content of phenolic hydroxyls was also observed (Perminova et al., 2005). 
In line with the above description of plausible structural changes of HS via reactions with various oxidants, the present work hypothesized that the oxidation of natural HA with $\mathrm{K}_{2} \mathrm{~S}_{2} \mathrm{O}_{8}$ would increase the proportion of suitable functional groups on HA molecules and thereby enhance their PTTE sorption abilities. The evolution of modified HA structures due to oxidation reactions vis-a-vis their mechanisms of PTTE sorption has been rarely reported in the literature. Most previous methods of humic acid oxidation were aimed at studying their structures mainly, whereas the present study was focused on a directed and effective chemical modification of humic acids targeted for enhanced PTTE adsorption. Therefore, the purposes of the present work are to (a) study the absorption of PTTEs $(\mathrm{Cu}, \mathrm{Pb}, \mathrm{Zn}$ and $\mathrm{Ni}$ ) by natural peat HA and the HA chemically modified by $\mathrm{K}_{2} \mathrm{~S}_{2} \mathrm{O}_{8}$, (b) examine the structural evolution of modified HA products using ${ }^{13} \mathrm{C}$ nuclear magnetic resonance (NMR) spectroscopy, and (c) qualitatively predict the PTTE adsorption mechanisms by the HA products. The above four PTTEs were chosen in this study because they are the most commonly occurring PTTEs posing toxic effects to living organisms. According to their toxicity to organisms, PTTEs can be arranged in the following order: $\mathrm{Hg}>\mathrm{Cu}>\mathrm{Zn}>\mathrm{Ni}>\mathrm{Pb}>\mathrm{Cd}>\mathrm{Cr}>\mathrm{Sn}>\mathrm{Fe}>\mathrm{Mn}>\mathrm{Al}$ (Zwolak et al., 2019).

\section{Materials and methods}

\subsection{Peat deposition characteristics}

For the extraction of HAs, an eutrophic peat from the deposit "Kommuna", located in the Tula region, Suvorov district, Russia, near the resort "Krainka", on the opposite side of the Cherepet' river floodplain, was used. The coordinates of the peat collection location is $54^{\circ} 07^{\prime} 36.8^{\prime \prime} \mathrm{N} 36^{\circ} 20^{\prime} 29.8^{\prime \prime} \mathrm{E}$. The peat bog at the specified deposit belongs to the class of floodplain and girder bogs, a subclass of floodplain bogs, a group of eutrophic bogs and a type of black alder bogs (Volkova, 2018). The peatbog length is $900 \mathrm{~m}$, the maximum width is $800 \mathrm{~m}$, and the area covered is 38 ha. The total capacity of the peat layer is from 1.5 to $5 \mathrm{~m}$. The surface is covered with an alder forest with a height of trees up to $10 \mathrm{~m}$ and thick underbrush. 
The degree of peat decomposition (humification; defined as the relative proportion of humification products of the entire peat substances) (Biester et al., 2014) at the selected location was $40-45 \%$. The reaction of the medium in the peat mass was weakly acidic $(\mathrm{pH}=5.9)$, the redox potential was positive $(126 \mathrm{mV})$, which indicated the predominance of oxidative processes in the peat mass. For the experiments, peat from the upper part of the deposit located above the water was used. The sample had a crumbly texture typical of peat and a dark brown color, which distinguished it from peat mud located under the water and represented by a plastic mass of black color.

\subsection{Isolation of humic acids from peat}

According to Lowe (1992), crushed and sifted through a 2-mm sieve peat was treated several times with a mixture of benzene-ethanol (1:1) in a ratio of peat: extractant $=1: 3$. For an exhaustive debituminization, the treatment was carried out until the extractable solution became almost colorless. After the extraction, the peat was dried at a temperature of $40-60^{\circ} \mathrm{C}$ for $8 \mathrm{~h}$ until the smell of benzene disappeared. Then, the peat was mixed with a solution of $0.1 \mathrm{M} \mathrm{NaOH}$ in the ratio of $1: 10$, kept on a water bath at $90^{\circ} \mathrm{C}$ for $3 \mathrm{~h}$ and stored undisturbed overnight. Afterwards, the alkaline solution was decanted and filtered. The extraction was repeated three times and the solution was collected and pooled together.

To isolate HA, the alkaline extract obtained was acidified with $6 \mathrm{M} \mathrm{HCl}$ to $\mathrm{pH}$ 1. Then, the supernatant of FA was filtered. The HA precipitate was washed with distilled water to $\mathrm{pH} \sim 6$, and the liquid phase was separated from the precipitate by centrifugation for $15 \mathrm{~min}$ at 8,000 rpm. The $\mathrm{HA}$ was dried over anhydrous $\mathrm{CaCl}_{2}$ at $20^{\circ} \mathrm{C}$ to constant weight and ground in an agate mortar to a finely mixed state.

\subsection{Oxidation of humic acids}

The oxidation of HA was carried out according to the method proposed for phenols (Sethna, 1951). A portion of the initial HA (3 g) was dissolved in $50 \mathrm{~mL}$ of $10 \% \mathrm{NaOH}$ solution, and then $50 \mathrm{~mL}$ of distilled water was added. Under vigorous 
stirring for $1 \mathrm{~h}, 15 \mathrm{mmol}$ of a saturated solution of $\mathrm{K}_{2} \mathrm{~S}_{2} \mathrm{O}_{8}$ was added to the resulting solution. The temperature of the mixture was maintained at $20^{\circ} \mathrm{C}$ in the water bath. The mixture was then stored undisturbed for $12 \mathrm{~h}$ after which the solid phase was separated from the liquid by filtration.

\section{$2.4{ }^{13}$ C NMR spectroscopy}

The distribution of HA C between the structural fragments was determined by ${ }^{13} \mathrm{C}$ NMR spectroscopy. The NMR characterization was performed at the Resource Center for Magnetic Resonance Research Methods of the St. Petersburg State University using the device Bruker Avance $400 \mathrm{WB}$ with a standard dual-channel sensor with a rotation system at a magic angle. A zirconium oxide rotor (4 mm) was used. The rotational frequency was set $12500 \mathrm{~Hz}$. To obtain the HA spectra, two methods were used: (1) the direct excitation method (the number of scans was 5000, the duration of the exciting pulse was $3.2 \mu \mathrm{s}$, the relaxation delay was $10 \mathrm{~s}$ ); and (2) the cross-polarization / rotation method at a magic angle - CP / MAS (the number of scans was 2500 , the contact duration was $500 \mu \mathrm{s}$, the relaxation delay was $3 \mathrm{~s}$ ). Processing of ${ }^{13} \mathrm{C}$ NMR spectra of HA samples, including phase, baseline (for direct excitation method), and manual integration adjustments, was performed using the ACD Labs program. The obtained and processed spectral parameters of the original and oxidized peat HA are presented in Table 1 and 2.

\subsection{Adsorption experiments}

Solutions of $\mathrm{Pb}, \mathrm{Zn}, \mathrm{Cu}$ and $\mathrm{Ni}$ inorganic salts (nitrates) dissolved in a medium containing of $20 \mathrm{mmol} \mathrm{KNO}_{3}$ at $\mathrm{pH} 5$ were used to study the absorption of PTTE cations by the natural and oxidized HA. The absorption of these PTTEs by the initial natural HA was studied at solution metal concentrations of $0.4,0.8,2$ and $4 \mathrm{mmol} / \mathrm{L}$ with a HA:solution ratio equal to 1:125. The absorption of PTTEs by the oxidized HA was studied at a maximum metal concentration of $4 \mathrm{mmol} / \mathrm{L}$. Concentrations of PTTEs in wastewater or sewage-applied soil solutions can be found in 0.4 to 4 $\mathrm{mmol} / \mathrm{L}$ range (Förstner and Wittmann, 2012), as employed in this study. 
243 Corresponding metal solutions $(25 \mathrm{~mL})$ were added to $0.2 \mathrm{~g}$ of HA and thoroughly

244

245

246

247

248

249

250

251

252

253

254

255

256

257

258

259

260

261

262

263

264

265

266

267

268

269

270

271 stirred by a magnetic stirrer at a temperature of $20^{\circ} \mathrm{C}$ for $4 \mathrm{~h}$ (the equilibrium time was decided based on a preliminary experiment). At the end of the experiment, the equilibrium solution was separated from the adsorbent using a syringe filter with a pore size of $0.2 \mu \mathrm{m}$. Concentrations of PTTEs in the filtered solution were determined by inductively coupled plasma atomic emission spectroscopy (ICPAES) using a Perkin Elmer Optima 5300 DV spectrometer. The amount of adsorbed metals was calculated from the difference between their concentrations in the initial and equilibrium solutions. The experiments were performed in triplicate.

\section{Results and discussion}

\subsection{Humic acids structures identified by ${ }^{13} \mathrm{C}$ NMR spectroscopy}

A general view of the ${ }^{13} \mathrm{C}$ NMR spectra of the initial and modified samples of $\mathrm{HA}$ is shown in Fig. 2. Analysis of the absorption spectra of $\mathrm{C}$ atoms in the corresponding ${ }^{13} \mathrm{C}$ NMR spectra confirmed the presence of aromatic and aliphatic fragments as well as various functional groups, and these results were consistent with the literature data on the structure of HA (Kalabin et al., 2000; Pretsch et al., 2009). To determine the structural parameters characterizing the fragment composition of HA, the whole spectrum was divided into a number of ranges (in accordance with the characteristic values of chemical shifts of $\mathrm{C}$ atoms) and their relative integral intensities were determined (Table 1).

A comparative analysis of the obtained quantitative results from ${ }^{13} \mathrm{C} N M R$ spectra allowed us to make a number of conclusions about the structural features of the initial and modified HA (Table 1 and Table 2). The indicator of the total aromaticity of the sample of the initial HA $f_{\text {ar }}$, which is one of the most important characteristics of the HA, was $40.68 \%$. The amount of aromatic atoms in the sample of the modified HA decreased slightly to $38.36 \%$. The ratio of the aromatic and aliphatic parts in the composition of the unmodified and modified HA was 0.83 and 0.89 , respectively. Thus, the content of aromatic HA fragments was lower than that 
272 of aliphatic ones, and this indicator practically did not change during the chemical 273 modification of the HA.

From the ${ }^{13} \mathrm{C}$ NMR spectra, the $\mathrm{O} / \mathrm{C}$ atomic ratios were calculated, which took into account the contents of carbonyl, phenol-containing fragments, oxygencontaining carbohydrate fragments and methoxyl groups in the HA composition. As seen from the data of Table 2, the $\mathrm{O} / \mathrm{C}$ atomic ratios for the initial natural and modified HA had very close values. The degree of oxidation of the aromatic core $\mathrm{O} / \mathrm{C}_{\mathrm{ar}}=0.32$ turned out to be the same. The degree of oxidation of the aliphatic component for the initial HA was higher than the aromatic one, and the value was 0.49. For the modified HA, this characteristic was somewhat reduced to a value of 0.41 .

Many properties of HA can be determined by the type and number of functional 284 groups in their composition. From the ${ }^{13} \mathrm{C}$ NMR spectra, the following conclusions could be made about the functional groups and fragments in the HA samples:

(1) The $\mathrm{C}$ content of carboxyl groups in the initial natural sample was 7.38\%. The concentration of carboxyl fragments in the modified HA increased to $9.39 \%$.

(2) The number of phenolic fragments $\left(\mathrm{C}_{\mathrm{oH}}\right.$ fen $)$, which was determined by the difference of the integrated intensities in the ranges of the $\mathrm{C}_{\mathrm{ar}}-\mathrm{O}$ and $\mathrm{CH}_{3} \mathrm{O}$ fragments in the ${ }^{13} \mathrm{C}$ NMR spectra, was $10.55 \%$ in the natural $\mathrm{HA}$, and in the modified sample this indicator slightly decreased to $10.04 \%$.

(3) The C content of ketone and quinoid groups in the modified HA was significantly higher than in the initial natural HA (4.67 and $0.2 \%$, respectively).

(4) Signals of C atoms in the region of $160-168 \mathrm{ppm}$ could be attributed to inorganic carbonates that were not part of the HA structure and corresponded to $\mathrm{Na}_{2} \mathrm{CO}_{3}(\delta \mathrm{C}=168 \mathrm{ppm})$ and $\mathrm{NaHCO}_{3}(\delta \mathrm{C} \approx 162 \mathrm{ppm})$.

(5) The presence of the lignin component in the peat group (as the most resistant to transformation under conditions of low oxygen access and low 

biological activity of peat bog) could be judged by the signals $\delta \mathrm{C} \approx 93$ $\operatorname{ppm}(\mathrm{C} \alpha, \beta-\mathrm{O}-4)$ and $\approx 56 \mathrm{ppm}\left(\mathrm{CH}_{3} \mathrm{O}\right.$ - groups) (Kalabin et al., 2000).

(6) The content of $\mathrm{C}_{\mathrm{alk}}-\mathrm{O}$ fragments in the natural HA sample was rather high (19.81\%), which also indicated the "immaturity" of the HA of the peat used. In the modified sample, this parameter dropped to $14.86 \%$.

In addition to the ratios above mentioned, another important observation from the point of view of HA properties is the ratio of hydrophilic and hydrophobic components in the macrostructures of HA. The hydrophilic components include oxygen-containing fragments $\left(\mathrm{C}=\mathrm{O}, \mathrm{C}_{\text {quin }}, \mathrm{COOH}, \mathrm{C}_{\mathrm{oH}}\right.$ fen $)$ and $\mathrm{C}_{\mathrm{alk}}-\mathrm{O}$ fragments. The hydrophobic part is represented by $\mathrm{C}$ - and $\mathrm{H}-$ substituted aromatic $\left(\mathrm{C}_{\mathrm{ar}}-\mathrm{H}, \mathrm{C}_{\mathrm{ar}}-\right.$ C) and alkyl $\mathrm{C}_{\mathrm{alk}}$ fragments of HA. The ratio of hydrophilic and hydrophobic parts of HA is characterized by properties such as solubility and reactivity. In both samples studied, the hydrophobic component predominated over the hydrophilic part of the HA molecules. In the modified sample, the content of hydrophilic fragments was $1.9 \%$ higher compared to the initial natural HA.

In the ${ }^{13} \mathrm{C}$ NMR spectra of the studied samples, a number of relatively narrow signals were observed (Fig. 2), which could be attributed to the following fragments and functional groups: $\delta \mathrm{C} 30$ ppm: $-\mathrm{CH}_{2}$ groups; 56 ppm: $\mathrm{OCH}_{3}, \mathrm{C}-\mathrm{NH}_{2} ; 72$ ppm: mono-, di - and polyhydroxy (carbohydrate) fragments, aliphatic alcohols; 105 ppm: acetal or ketal carbohydrate fragments of the polysaccharide chain; 128 ppm: a Csubstituted aromatic ring; 149 and 153 ppm: O-substituted aromatic fragment; 172 ppm: $\mathrm{COOH}, \mathrm{COOR}$ and CONH (Kalabin et al., 2000).

Thus, the most significant changes in the structure of HA as a result of their oxidation with $\mathrm{K}_{2} \mathrm{~S}_{2} \mathrm{O}_{8}$ was an increase in the number of carboxyl groups as well as a significant increase in the contents of ketone and quinoid fragments.

\subsection{Adsorption of PTTEs by natural and oxidized humic acids}


The adsorption of four studied heavy metals $(\mathrm{Pb}, \mathrm{Zn}, \mathrm{Cu}, \mathrm{Ni})$ on the natural peat HA (Fig. 3) was satisfactorily described by the Langmuir isothermal model (Eq. 1):

$$
\mathrm{q}=\mathrm{K}_{\mathrm{L}} \mathrm{Q}_{\max } \mathrm{c} /\left(1+\mathrm{K}_{\mathrm{L}} \mathrm{c}\right)=\mathrm{Q}_{\max }\left[1-1 /\left(1+\mathrm{K}_{\mathrm{L}} \mathrm{c}\right)\right]
$$

where, $\mathrm{q}$ is the amount of the component adsorbed by the solid phase, related to its mass; $\mathrm{c}$ is the equilibrium concentration of the component in the solution;

$\mathrm{K}_{\mathrm{L}}$ is empirical adsorption coefficient or Langmuir coefficient characterizing the bond strength between the element and the sorption sites and the energy of their interaction;

$\mathrm{Q}_{\max }$ is the maximum adsorption, or the capacity of the Langmuir monolayer.

The data showed that the $\mathrm{K}_{\mathrm{L}}$ values decreased in the following order: $\mathrm{Pb}^{2+}>$ $\mathrm{Cu}^{2+}>\mathrm{Ni}^{2+}>>\mathrm{Zn}^{2+}$, and the $\mathrm{Q}_{\max }$ values decreased in the following order: $\mathrm{Pb}^{2+} \geq$ $\mathrm{Cu}^{2+}>\mathrm{Zn}^{2+}>\mathrm{Ni}^{2+}$ (Table 3). Therefore, $\mathrm{Pb}^{2+}$ and $\mathrm{Cu}^{2+}$ ions had the highest bond strength with HA. The $\mathrm{Zn}^{2+}$ cations were retained by the natural peat $\mathrm{HA}$ much weaker bond strength, and thus was likely to have greater mobility in the free-state. The natural peat $\mathrm{HA}$ also had the highest absorption capacity with respect to $\mathrm{Pb}^{2+}$ and $\mathrm{Cu}^{2+}$ cations, and the lowest with respect to $\mathrm{Ni}^{2+}$ cations.

It is known that at a low adsorbent loading, adsorption is carried out mainly at the adsorption sites with the highest affinity for the adsorbate. Moreover, it must be borne in mind that for different PTTE cations the adsorption sites may have different chemical affinities (Pinskii, 1997; Minkina et al., 2011). As the adsorption sites are gradually filled with PTTE cations, the bond strength between them decreases due to the fact that the adsorption sites that most weakly interact with the adsorbate remain unoccupied (Pinskii, 1997; Minkina et al., 2011) In addition, the adsorbed cations affect each other, competing for or preventing the adsorption of specific cations from the solution.

The PTTE cations are most strongly adsorbed in the dense part of the electrical double layer due to donor-acceptor or coordination bonds. Due to these interactions, inner-sphere surface complex compounds are formed (Minkina et al., 2016). This type of adsorption is called "specific adsorption", and here the adsorbent shows a 
high selectivity for the adsorbing cation. The absorbed $\mathrm{Cu}^{2+}$ cations in such cases were shown to form octahedral chelate-type inner-sphere complexes with HA, while $\mathrm{Zn}^{2+}$ cations were prone to interaction with soil HA components as silicates, carbonates and hydro/oxides Fe and Mn (Minkina et al., 2016). The formation of ternary complexes is also possible, in which the central position is occupied by the $\mathrm{Cu}^{2+}$ ion associated with organic and mineral components. In some cases, there is formation of poorly soluble salts of metals with HA (Pinskii et al., 2018). However, these processes are poorly studied and unlikely to happen in the presently studied system.

The absorption of the four PTTEs $(\mathrm{Zn}, \mathrm{Pb}, \mathrm{Cu}, \mathrm{Ni})$ at a solution concentration of $4 \mathrm{mmol} / \mathrm{L}$ was compared between the natural and oxidized HA with an adsorbent loading of $500 \mathrm{mmol} / \mathrm{kg}$, and the results are shown in Fig. 4. Experimental results demonstrated that the oxidation of peat $\mathrm{HA}$ with $\mathrm{K}_{2} \mathrm{~S}_{2} \mathrm{O}_{8}$ led to an increase in its absorption of all the studied PTTEs. The increase in adsorption of different metals was expressed in different degrees. The absorption of $\mathrm{Pb}^{2+}, \mathrm{Ni}^{2+}, \mathrm{Zn}^{2+}$ and $\mathrm{Cu}^{2+}$ increased by $16.3,14.2,10.6$ and $6.9 \%$, respectively, on the modified HA as compared to the natural $\mathrm{HA}$. The oxidation of peat $\mathrm{HA}$ by $\mathrm{K}_{2} \mathrm{~S}_{2} \mathrm{O}_{8}$ led to an increase in the absorption of PTTEs possibly by an increase in the content of carboxylic groups (from 7.38 to $9.39 \%$ ) and ketone and quinoid groups (from 0.2 to $4.67 \%$ ) in the HA structure, as evidenced from the ${ }^{13} \mathrm{C}$ NMR results of this study.

Lakatos et al. (1977) using the method of electron paramagnetic resonance (EPR) showed that the $\mathrm{Cu}^{2}+$ cation was bound on HA by forming inner-sphere complexes with the participation of carboxyl and amino groups. Similarly, McBride (1982) investigating the interaction of $\mathrm{Cu}^{2+}$ with $\mathrm{HA}$ by the same EPR method indicated that $\mathrm{Cu}^{2+}$ formed a complex with oxygen ligands, and the -OH groups of the adsorbent surface were included in the coordination sphere of the hydrated ions of $\mathrm{Cu}^{2+}$.

The presence of quinone and semiquinone fragments in HA would make possible reactions via a free radical mechanism (Sorokina, 2014). Free radicals, possessing a large amount of energy, are one of the main reaction centers in the 


\section{3}

molecules of humus compounds (Chukov, 2001). Many sources contain information on the decrease in the number of free radicals in humic compounds when they interact with the cation of copper, iron, manganese and other heavy metals (Babanin et al., 1983).

\section{Conclusions}

This study showed that natural humic acids isolated from a eutrophic peat were highly efficient in the immobilization of important PTTEs such as $\mathrm{Pb}, \mathrm{Cu}, \mathrm{Ni}$, and Zn following a persulfate oxidation. The adsorption features of the PTTEs depended on the chemical properties of the elements, and were satisfactorily described by the Langmuir isothermal model. Oxidation of the natural HA with $\mathrm{K}_{2} \mathrm{~S}_{2} \mathrm{O}_{8}$ led to an increase in the number of carboxyl groups, and contents of ketone and quinoid fragments of HA. Oxidized HA absorbed a greater amount of PTTEs compared to the original natural HA. Thus, the chemical modification of HA through oxidation could enable HA to be used for practical remediation of wastewater contaminated with PTTEs. Future research should focus on economically feasible and environmentally benign methods for applying oxidized and/or directly carboxylated HA for the remediation of PTTEs. The behavior and stability of salts and complex compounds made of humic acids and PTTEs in the real environment should also be studied in detail.

\section{Acknowledgements}

The study was supported by the Russian Foundation for Basic Research (Project No. 18-04-00274). 


\section{References}

416 1. Babanin, V.F., Ermilov, S.S., Morozov, V.V., Orlov, D.S., Falkov, I.G., 417 1983. Study of the interaction of humic acid with metal cations using electron 418 paramagnetic resonance and magnetic measurements. Sov. Soil Sci. 7, 115-120 (in 419 Rus).

420 2. Behrman, E.J., 2006. The Elbs and Boyland-Sims peroxydisulfate 421 oxidations. Beilstein J. Org. Chem .46, 22.

422 3. Biester, H., Knorr, K.-H., Schellekens, J., Basler, A., and Hermanns, Y.-M., 2014. Comparison of different methods to determine the degree of peat decomposition in peat bogs. Biogeosciences. 11, 2691-2707. 4. Boguta, P, Sokołowska, Z., 2016. Interactions of $\mathrm{Zn}(\mathrm{II})$ ions with humic acids isolated from various type of soils. Effect of $\mathrm{pH}, \mathrm{Zn}$ Concentrations and

427 Humic Acids Chemical Properties. PLoS ONE 11(4): e0153626. doi:10.1371/journal.pone.0153626

5. Chukov, S.N., 2001. Structural and functional parameters of soil organic matter under anthropogenic conditions. St. Petersburg State University Publishing House, St. Petersburg (in Rus).

6. Datta, A., Sanyal, S.K., Saha, S., 2001. A study of natural and synthetic humic acids and their complexing ability towards cadmium. Plant Soil. 235, 115125.

7. Förstner, U., Wittmann, G. T. W., 2012. Metal pollution in the aquatic environment, Springer Science \& Business Media, 488 p.

8. Ghabbour, E.A., Davies, G., 2007. Humic substances: Structure, Models and Functions. Royal Society of Chemistry, 402 p.

439 9. Gjessing, E.T., 1976. Physical and chemical characteristics of aquatic

440 humus. Ann Arbor Science, Ann Arbor.

10. Hatten, J., Goñi, M., 2016. Cupric oxide (CuO) oxidation detects pyrogenic carbon in burnt organic matter and soils. PLoS One. 11(3), e0151957. doi: 10.1371/journal.pone.0151957. 
444 11. Kabata-Pendias, A., Pendias, H., 1992. Trace elements in soils and plants, 2nd ed. CRC Press, Boca Raton Ann Arbor, London.

12. Kalabin, G.A., Kanitskaya, L.V., Kushnarev, D.F., 2000. Quantitative NMR

spectroscopy of natural organic raw materials and products of its processing. Chemistry, Moscow (in Rus).

13. Lakatos, B., Tibai T., Meisel, J., 1977. EPR spectra of humic acids and their metal complexes. Geoderma. 19, 319-338.

14. Lebedeva, G.F., Yarkova, T.Ya., Platonov, V.V., Proskuryakov, V.A., 2005. Chemical modification of peat humic acids to increase their bioactivity. Russian Journal of Applied Chemistry. 78,1360-1363.

15. Loffredo, E., Senesi, N., 2006. Fate of anthropogenic organic pollutants in soils with emphasis on adsorption/desorption processes of endocrine disruptor compounds. Pure Appl. Chem. 78, 947-961.

16. Lowe, L.E., 1992. Studies on the nature of sulphur in peat humic acids from the Fraser river delta, British Columbia. Sci. Total Environ. 113, 133-145.

17. Martin, F., Gonzalez-Vila, F.J., 1984. Persulfate oxidation of humic acids extracted from three different soils. Soil Biol. Biochem. 16, 207-210.

18. Martin, F., Sáiz·Jiménez, C., González-Vila, F.J., 1982. The persulfate oxidation of a soil humic acid. Soil Sci. 132, 200-203.

19. McBride, M.B., 1982. $\mathrm{Cu}^{2+}$ adsorption characteristics of aluminum hydroxide and oxyhydroxides. Clay Clay Miner. 30, 21-28.

20. Meneghel, R., Petit-Sarlotte, C., Bloch, J., 1972. Sur la caracterisation et l'isolement des produits de degradation d'un acide humique apres oxydation peracetique. B. Soc. Chim. Fr. 7, 2997-3001.

21. Minkina, T.M., Mandzhieva, S.S., Sushkova, S.N., Pinskii, D.L., Antonenko, E.M., 2011. Effect of the particle-size distribution on the adsorption of copper, lead, and zinc by chernozemic soils of Rostov oblast. Eurasian Soil Sci+. 18, 1193-1200.

472 22. Minkina, T.M., Soldatov, A.V., Nevidomskaya, D.G., Motuzova, G.V., Podkovyrina, Yu.S., Mandzhieva, S.S., 2016. New approaches to studying heavy 
474 metals in soils by X-ray absorption spectroscopy (XANES) and extractive 475 fractionation. Geochem Int+ .54, 197-204.

476 23. Nguyen, M.T., Kryachko, E.S., Vanquickenborne, L.G., 2003. General and 477 theoretical aspects of phenols, in: Rappoport, Z. (Ed.), The Chemistry of Phenols. 478 John Wiley \& Sons, The Atrium, Southern Gate, Chichester, West Sussex, 479 England, pp. 1-198.

480 24. Orlov, D.S., 1995. Humic substances of soils and general theory of 481 humification. CRC Press, Rotterdam. 25. Pinskii, D.L., 1997. Ion exchange processes in soils. ONTI PNC RAN, 483 Pushchino (in Rus). 26. Perelomov, L. V., Perelomova, I. V., Venevtseva, Y. L., 2016. The toxic 485 effects of trace elements on male reproductive health. Hum. Physiol. 42 (4), 454462. https://doi.org/10.1134/S0362119716030130

27. Perelomov, L., Sarkar, B., Sizova, O., Chilachavaa, K., Shvikin, A., Perelomova, I., Atroshchenko Yu., 2018. Zinc and lead detoxifying abilities of humic substances relevant to environmental bacterial species. Ecotox. Environ. Safe. $151,178-183$.

28. Perminova, I.V.; Hatfield, K., 2005. Remediation chemistry of humic substances: theory and implications for technology, in: Hatfield, Hertkorn, Perminova (Eds.), Use of humic substances to remediate polluted environments: from theory to practice. NATO Science Series IV: Earth and Environmental Sciences 52. Springer, Dordrecht, pp 3-36.

29. Perminova, I.V., Kovalenko, A.N., Schmitt-Kopplin, Ph., Hatfield, K., Hertkorn, N., Belyaeva, E.Y., Petrosyan, V.S., 2005. Design of quinonoid-enriched humic materials with enhanced redox properties. Environ Sci. Technol. 39, 85188524.

30. Pinskii, D.L., Minkina, T.M., Bauer, T.V., Nevidomskaya, D.G., 501 Mandzhieva, S.S., Burachevskaya, M.V., 2018. Copper adsorption by chernozem 502 soils and parent rocks in Southern Russia. Geoch Int+. 56, 266-275. 
503 31. Pretsch, E., Buhlmann, Ph., Badertscher, M. 2009. Structure determination

504 of organic compounds. Tables of spectral data. Springer-Verlag, Berlin Heidelberg, $505433 \mathrm{p}$.

506 32. Schnitzer, M., Ortiz de Serra, M.L., 1973. The chemical degradation of a 507 humic acid. Can. J. Chem. 51, 1554-1566.

508 33. Sethna, S.M., 1951. The Elbs persulfate oxidation. Chem. Rev. 49,91-101.

509 34. Sharp, J.H., 1973. Total organic carbon in seawater. Comparison of

510 measurements using persulfate oxidation and high temperature combustion. Mar.

511 Chem. 1, 211-229.

512 35. Sorokina T.A., 2014. Preparation and use of bioavailable iron compounds 513 stabilized by humic substances. Dissertation, Moscow State University, Moscow 514 (in Rus).

515 36. Stevenson., F.J., 1982. Humus chemistry. Genesis, composition, reactions. 516 Wiley Interscience, New York.

517 37. Tung, T. X., Xu, D., Zhang, Y., Zhou, Q., Wu, Z., 2019. Removing humic 518 acid from aqueous solution using titanium dioxide: A Review. Polish Journal of 519 Environmental Studies. 28(2), 529-542. https://doi.org/10.15244/pjoes/85196. 520 38. Uliana, M.P., Vieira, Y.W., Donatoni, M.C., Corrêa, A.G., Brocksom, U., 521 Brocksom, T.J., 2008. Oxidation of mono-phenols to para-benzoquinones: a 522 comparative study. J. Braz. Chem. Soc. 19(8), 1484-1489.

523 http://dx.doi.org/10.1590/S0103-50532008000800007

524 39. Valencia, S., Marín, J., Restrepo, G., 2018. Photocatalytic degradation of 525 humic acids with titanium dioxide embedded into polyethylene pellets to enhance 526 the postrecovery of catalyst. Environmental Engineering Science. 35(3).

527 https://doi.org/10.1089/ees.2017.0091

528 40. Vardhan, K.H., Kumar, P.S., Panda, R.C., 2019. A review on heavy metal 529 pollution, toxicity and remedial measures: Current trends and future perspectives.

$530 \quad$ Journal of Molecular Liquids. 290, 111197.

531 https://doi.org/10.1016/j.molliq.2019.111197 
532 41. Volkova, E.M., 2018. Bogs of the Central Russian Upland: the genesis, 533 structural and functional features and environmental value. Dissertation, Komarov 534 Botanical Institute of RAS, St-Petersburg (in Rus).

535 42. Yuthawong, V., Kasuga, I., Kurisu, F., Furumai, H., 2019. Molecular-level 536 changes in dissolved organic matter compositions in lake Inba water during 537 KMnO4 oxidation: assessment by orbitrap mass spectrometry. Journal of Water 538 and Environment Technology. 17(1), 27-39. doi: 10.2965/jwet.18-043

539 43. Zhou, L., Yuan, L., Zhao, B., Li, Y., Lin, Z., 2019. Structural characteristics 540 of humic acids derived from Chinese weathered coal under different oxidizing 541 conditions. PLoS ONE. 14(5), e0217469.

542 https://doi.org/10.1371/journal.pone.0217469

543 44. Zwolak, A., Sarzyńska, M., Szpyrka, E., Stawarczyk K., (2019). Sources of 544 soil pollution by heavy metals and their accumulation in vegetables: a Review.

545 Water Air Soil Pollut. 230,164.

546 https://doi.org/10.1007/s11270-019-4221-y 
548 Figure captions:

549 Fig. 1 Scheme of the reactions of Elbs (a) and Boyland-Sims (b).

550 Fig. $2{ }^{13} \mathrm{C}$ NMR spectra of initial HA (a) and oxidized HA (b) obtained by the 551 direct excitation method.

552 Fig. 3 Adsorption isotherms of $\mathrm{Pb}(\mathrm{a}), \mathrm{Zn} \mathrm{(b),} \mathrm{Cu}(\mathrm{c})$, and $\mathrm{Ni}(\mathrm{d})$ with natural peat 553 HA.

554 Fig. 4 Adsorption of PTTEs by natural and oxidized $\mathrm{HA}$ at $\mathrm{pH}=5$, and metal 555 concentration $=4 \mathrm{mmol} / \mathrm{L}$. Error bars represent standard deviation.

556 
559 Table 1 Fragment compositions of natural and chemically modified HA

\begin{tabular}{|c|c|c|c|c|c|c|c|c|c|}
\hline \multirow[b]{2}{*}{ HA } & \multicolumn{9}{|c|}{ Content of $\mathrm{C}$ atoms in the structural fragments (relative integrated areas, \%) } \\
\hline & $\begin{array}{c}\mathrm{C}=\mathrm{O} \\
(220- \\
186 \\
\text { ppm) }\end{array}$ & $\begin{array}{c}\mathrm{C}_{\text {quin }} \\
(186- \\
180 \\
\mathrm{ppm})\end{array}$ & $\begin{array}{c}\mathrm{COOH} \\
\mathrm{COOR} \\
(180- \\
168 \\
\mathrm{ppm})\end{array}$ & $\begin{array}{c}\mathrm{CO}_{3}{ }^{2-} \\
\mathrm{HCO}_{3}{ }^{-} \\
(168- \\
160 \\
\mathrm{ppm})\end{array}$ & $\begin{array}{c}\mathrm{C}_{\mathrm{ar}-\mathrm{O}} \\
(160- \\
140 \\
\mathrm{ppm})\end{array}$ & $\begin{array}{c}\mathrm{C}_{\mathrm{ar}}-\mathrm{H}, \\
\mathrm{C}_{\mathrm{ar}}-\mathrm{C} \\
(140- \\
106 \\
\mathrm{ppm})\end{array}$ & $\begin{array}{c}\mathrm{C}_{\text {alk- }} \\
\mathrm{O}, \\
\mathrm{C}_{\alpha \beta^{-}} \\
\mathrm{O}-4 \\
(106- \\
58 \\
\mathrm{ppm})\end{array}$ & $\begin{array}{c}\mathrm{CH}_{3} \mathrm{O} \\
(58-54 \\
\text { ppm })\end{array}$ & $\begin{array}{c}\mathrm{C}_{\text {alk }} \\
(54-0 \\
\mathrm{ppm})\end{array}$ \\
\hline Natural & 0.2 & 0.43 & 7.38 & 2.75 & 13.04 & 27.64 & 19.81 & 2.49 & 26.28 \\
\hline $\begin{array}{l}\text { Chemically } \\
\text { modified }\end{array}$ & 4.67 & 1.31 & 9.39 & 3.08 & 12.24 & 26.12 & 14.86 & 2.2 & 26.12 \\
\hline
\end{tabular}


Table 2 Indicators of the structural features of natural and chemically modified HA

\begin{tabular}{|c|c|c|c|c|c|c|c|c|}
\hline & \multicolumn{8}{|c|}{ Indicators } \\
\hline & $\begin{array}{c}\text { Total } \\
\text { aromaticity } \\
\quad f_{a r}{ }^{a} \\
\left(f_{a r}=P_{C a r O}\right. \\
\left.+P_{C a r H, C}\right)\end{array}$ & $\begin{array}{c}\text { Ratio of } \\
\text { aliphatic } \\
\text { and } \\
\text { aromatic } \\
\text { parts in } \\
H A \\
C_{a r} / C_{\text {alk }} \\
\\
\left(C_{a r} / C_{\text {alk }}\right. \\
=f_{a r} \\
/\left(C_{\text {alk }} \mathrm{O}\right. \\
+\mathrm{CH}_{3} \mathrm{O} \\
\left.\left.+\mathrm{C}_{\text {alk }}\right)\right)\end{array}$ & 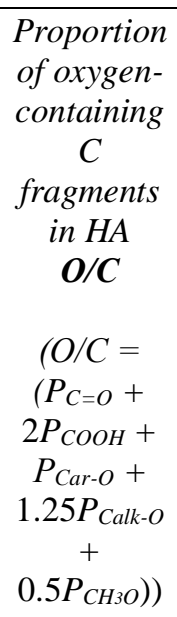 & $\begin{array}{c}\text { Degree } \\
\text { of } \\
\text { oxidation } \\
\text { of the } \\
\text { aromatic } \\
\text { core of } \\
\text { HA } \\
\text { O/Car } \\
\left(O / C_{a r}=\right. \\
\left.C_{a r}-O / f_{a r}\right)\end{array}$ & $\begin{array}{c}\text { Degree of } \\
\text { oxidation of } \\
\text { aliphatic } \\
\text { component } \\
\text { of } \mathrm{HA} \\
\text { O/C } \boldsymbol{C}_{\text {alk }} \\
\\
\left(\mathrm{O} / \mathrm{C}_{\text {alk }}\right. \\
=\left(\mathrm{C}_{\text {alk }} \mathrm{O}+\right. \\
\left.\mathrm{CH}_{3} \mathrm{O}\right) /\left(\mathrm{C}_{\text {alk }}-\right. \\
\mathrm{O}+\mathrm{CH}_{3} \mathrm{O} \\
\left.\left.+\mathrm{C}_{\text {alk }}\right)\right)\end{array}$ & $\begin{array}{c}C \text { content } \\
\text { associated } \\
\text { with } \\
\text { phenol } \\
\text { groups } \\
\text { Coufen } \\
\\
\left(C_{\text {OHfen }}=\right. \\
\left(C_{\text {ar }} \mathrm{O}-\right. \\
\left.\mathrm{CH}_{3} \mathrm{O}\right)\end{array}$ & $\begin{array}{c}\text { Content of } \\
\text { hydrophilic } \\
\text { components } \\
\boldsymbol{H L}, \boldsymbol{\%} \\
\\
(H L= \\
(\mathrm{C}=\mathrm{O}+ \\
C_{\text {quin }}+ \\
\mathrm{COOH}+ \\
\mathrm{CoH}_{f e n}+ \\
\left.C_{\text {alk }} \mathrm{O}\right)\end{array}$ & $\begin{array}{c}\text { Content of } \\
\text { hydrophobic } \\
\text { components } \\
\boldsymbol{H B}, \boldsymbol{\%} \\
\begin{array}{c}\left(H B=\left(C_{a r}-\right.\right. \\
H+C_{a r}-C \\
\left.\left.+C_{a l k}\right)\right)\end{array}\end{array}$ \\
\hline Natural & 40.68 & 0.83 & 0.54 & 0.32 & 0.49 & 10.55 & 38,37 & 53,92 \\
\hline $\begin{array}{l}\text { Chemically } \\
\text { Modified }\end{array}$ & 38.36 & 0.89 & 0.55 & 0.32 & 0.41 & 10.04 & 40,27 & 52,24 \\
\hline
\end{tabular}


$566 \quad$ Figures

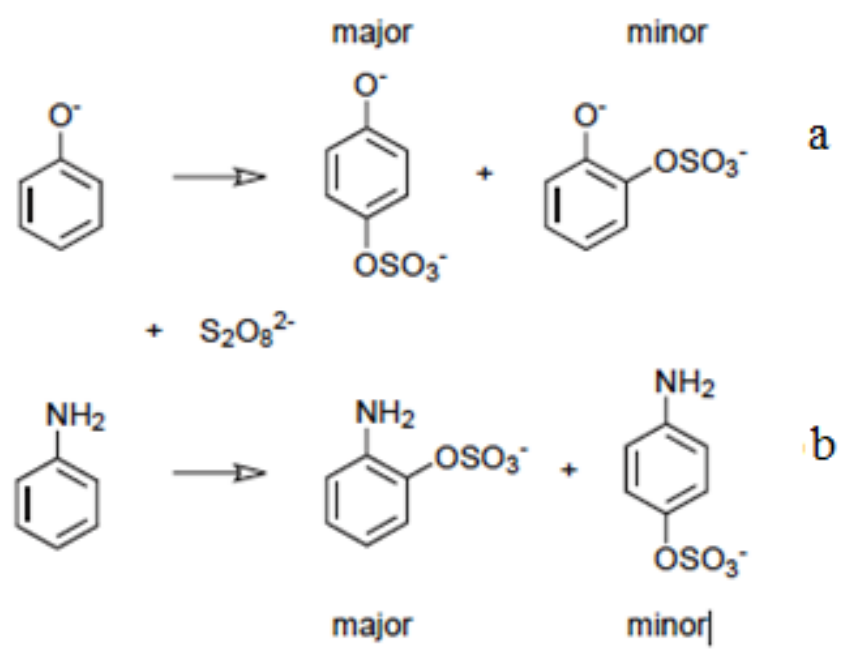

567

568 Fig. 1

569 


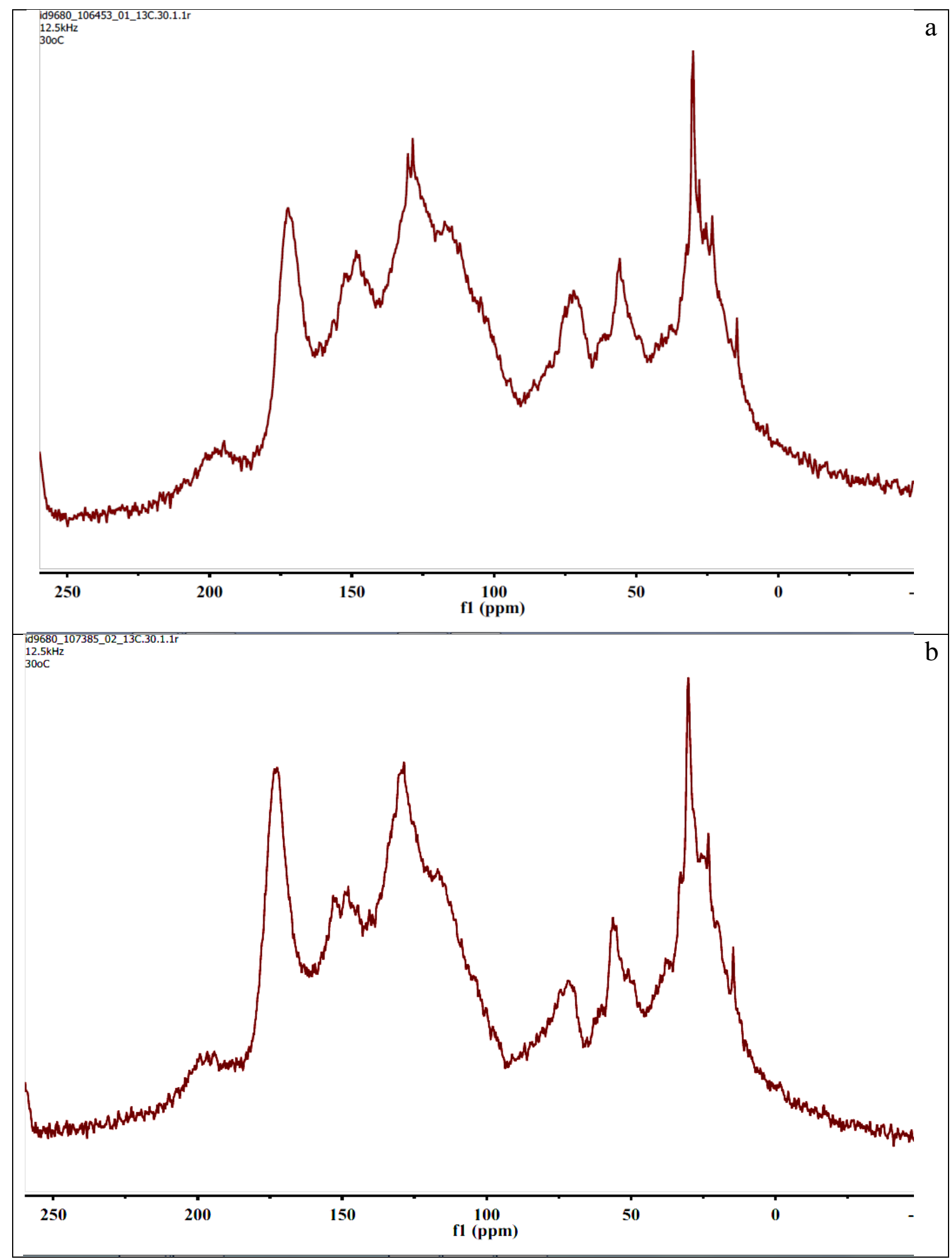

571 Fig. 2

572 
a

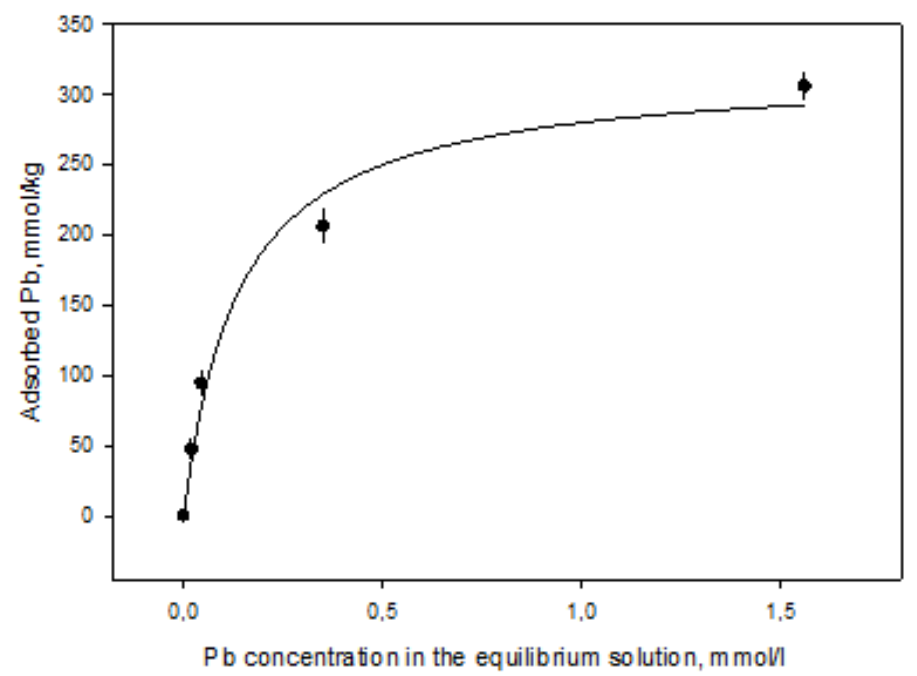

c

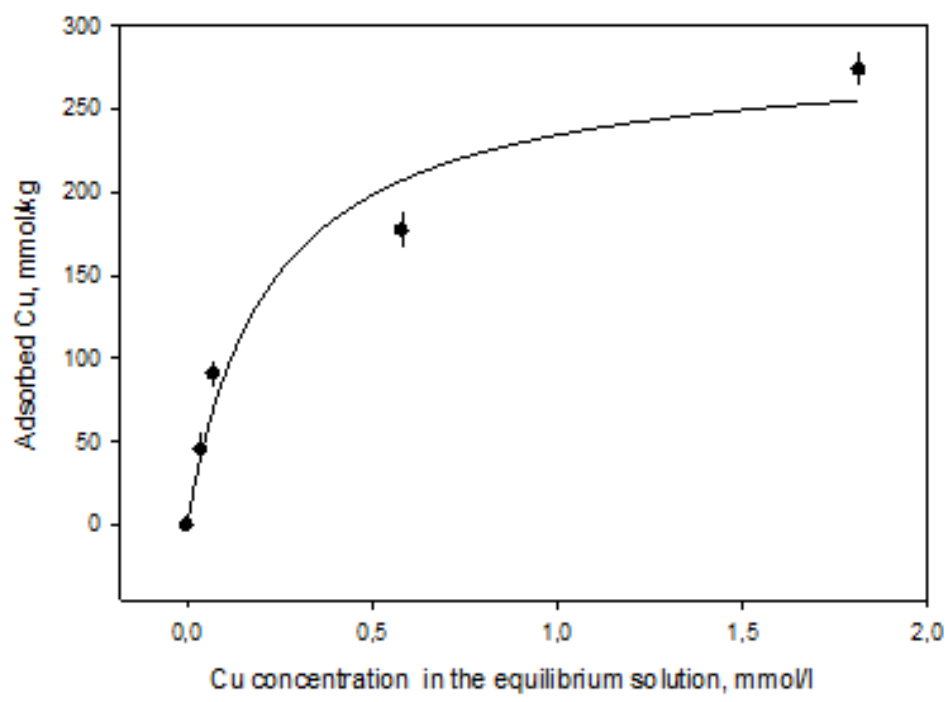

$573 \quad$ Fig. 3

574 b

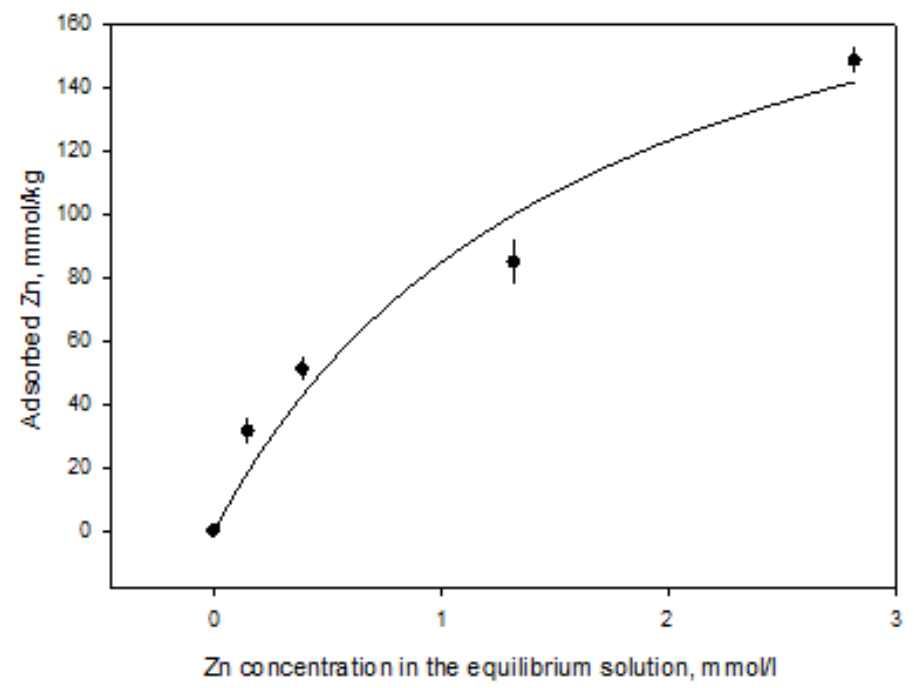

d

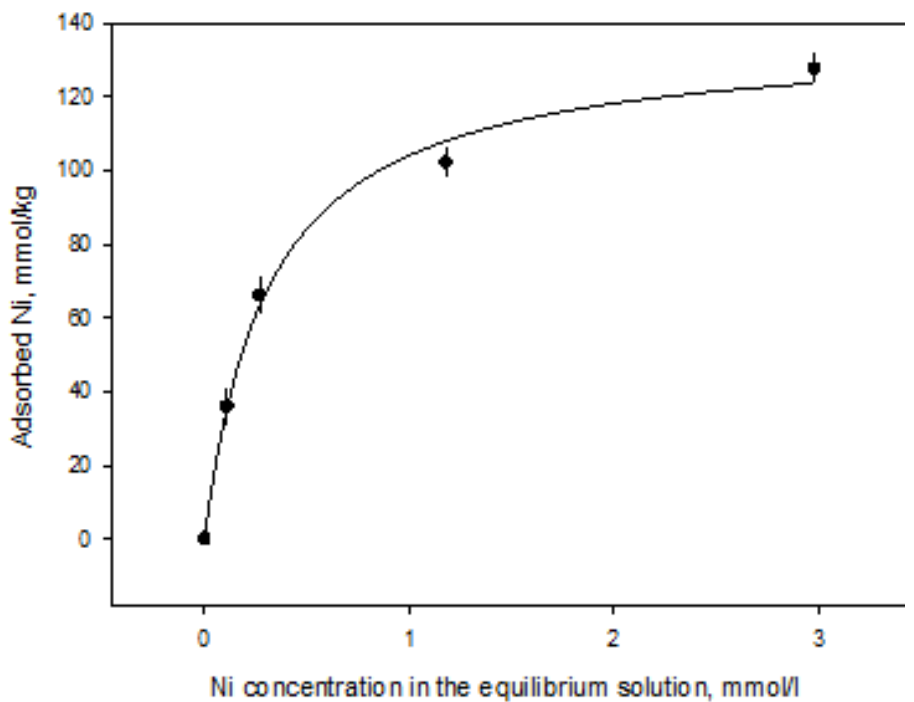

Ni concentration in the equilibrium solution, mmoll 


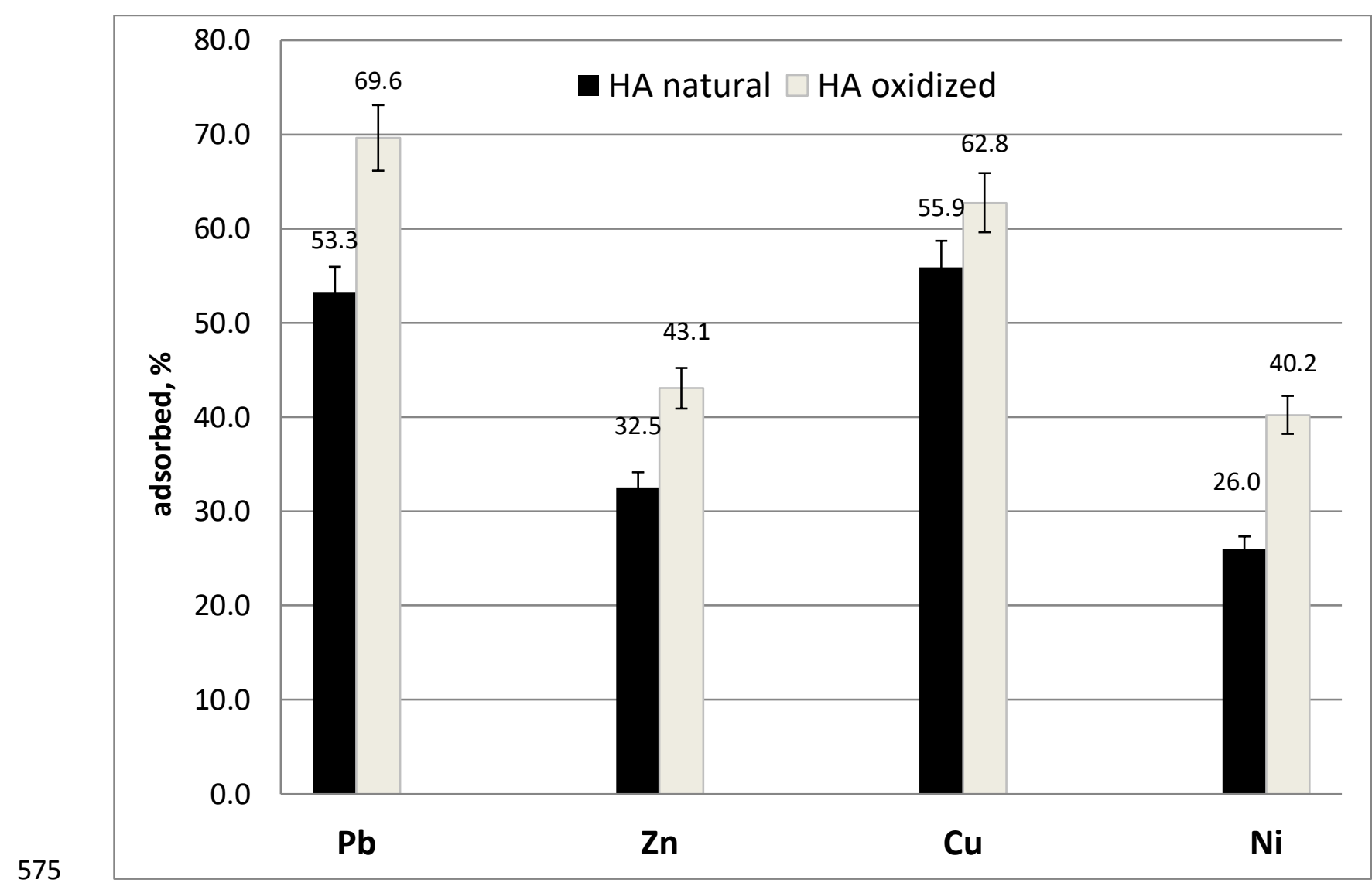

576

$577 \quad$ Fig. 4.

578 